\title{
CORRECTION NOTE
}

\section{'ON THE VALIDITY OF THE QUADRATIC UTILITY APPROACH IN MEAN- VARIANCE PORTFOLIO ANALYSIS: AN EMPIRICAL TEST, \\ De Economist, 127 (1979), pp. 422-445}

Page 433 - line 14 read $\left(\begin{array}{c}k \\ k-1\end{array}\right)$ instead of $\left(\frac{k}{k-1}\right)$

On the same page: The estimation procedure used in our study does not belong to the class of estimators suggested by Goldberger, because our $\mathbf{H}$ does not satisfy the sufficient conditions for positive definiteness. The estimates presented for non-linear procedures minimised the quadratic form,

\section{I'WI}

where $\mathbf{I}^{\prime}$ is a $(k-1 \mathbf{x l})$ vector whose elements are all unity. It may be noted that $\operatorname{Tr}(\mathbf{H} \overline{\mathbf{W}})$ in the paper and $I^{\prime} \overline{\mathbf{W}} \mathbf{l}$ mentioned here are identical.

D. K. Bhattacharyya 